\title{
Screening and brief intervention training for HIV health-care workers in sub-Saharan Africa
}

\author{
Richard Spence \\ From International Network on Brief Interventions for Alcohol Problems (INEBRIA) Meeting 2011 \\ Boston, MA, USA. 21-23 September 2011
}

Screening and feedback, brief intervention, and motivational interviewing have shown efficacy for reducing alcohol consumption. However, current protocols have been designed for Western settings. The present study adapted the methods to cultural and socioeconomic conditions in three developing African countries (Botswana, Tanzania, and Namibia). An intervention and associated curriculum was developed to train health-care workers to screen all patients and deliver a brief motivational intervention (BMI). A pocket guide and patient handouts were developed as implementation aids. Local beverages were referenced as standardized equivalents of beer, wine, and liquor. Materials were produced in English and prevalent local languages. Ministries of Health in each country adopted the methods as a strategy to reduce risky alcohol consumption and associated HIV infection risk in targeted areas. Based on follow-up surveys 60 days after the training, $64 \%$ of health-care workers in Tanzania and $94 \%$ in Namibia began using BMI for an average of $25 \%$ and $30 \%$ of their patients. Based on 14 clinician respondents in each country, a total of 252 Tanzanian patients and 424 Namibian patients received BMI in the two months following training. Implementation barriers included time, perceived stigma, and perceived patient resistance. The training and follow-up surveys document the health-care workers' need for a culturally relevant brief intervention to address risky alcohol use in an HIV prevention setting in sub-Saharan Africa. Follow-up plans include streamlined delivery methods, implementing monitoring and evaluation tools, and providing refresher training sessions.

Published: 9 October 2012

School of Social Work, University of Texas, Austin, TX, USA
doi:10.1186/1940-0640-7-S1-A72

Cite this article as: Spence: Screening and brief intervention training for HIV health-care workers in sub-Saharan Africa. Addiction Science \& Clinical Practice 2012 7(Suppl 1):A72.
Submit your next manuscript to BioMed Central and take full advantage of:

- Convenient online submission

- Thorough peer review

- No space constraints or color figure charges

- Immediate publication on acceptance

- Inclusion in PubMed, CAS, Scopus and Google Scholar

- Research which is freely available for redistribution (c) 2012 Spence; licensee BioMed Central Ltd. This is an Open Access article distributed under the terms of the Creative Commons Attribution License (http://creativecommons.org/licenses/by/2.0), which permits unrestricted use, distribution, and reproduction in any medium, provided the original work is properly cited. 